\title{
TRANSMITIR E HERDAR: O ESTUDO DOS FENÔMENOS EDUCATIVOS EM UMA PERSPECTIVA INTERGERACIONAL
}

\author{
KIMI TOMIZAKI
}

\begin{abstract}
RESUMO: O objetivo deste artigo é promover uma discussão sobre a potencialidade analítica e metodológica da abordagem geracional para as pesquisas que assumem como objeto de investigação a educação, especialmente, nas análises sociológicas dos fenômenos educativos. Para tanto, apresentaremos uma discussão sobre a noção de geração e seu uso nas ciências sociais, a partir do célebre trabalho de Karl Mannheim, mas em diálogo com outros autores contemporâneos que têm se debruçado sobre a análise das relações intergeracionais, tendo em vista destacar os aspectos fundamentais que caracterizaram o fenômeno geracional como uma situação social específica.
\end{abstract}

Palavras-chave: Gerações. Socialização. Sociologia da Educação.

TRANSMITTING AND INHERITING: THE STUDY OF EDUCATIONAL PHENOMENA FROM AN INTERGENERATIONAL PERSPECTIVE

ABSTRACT: This paper aims to promote a discussion on the analytical and methodological potential of the generational approach for research studies investigating education, especially in the sociological analysis of educational processes. To do so, it presents a discussion about the idea of generations and its use in social sciences according to the work of Karl Mannheim, as well as of other authors, to detach the fundamental aspects characterizing the generational phenomenon as a specific social circumstance. Finally, it discusses how the generational approach can imply a radicalization of the sociological analysis of the educational processes.

Key words: Generations. Socialization. Educational sociology.

Doutora em Educação e professora de Sociologia na Faculdade de Educação da Universidade de São Paulo (USP). E-mail: kimi@usp.br 
Transmitir e herdar: o estudo dos fenômenos educativos...

\section{Introdução}

Eu entrava em um grande porão povoado por uma multidão anônima, densa e silenciosa; ao lado, havia um espaço de baile onde dançavam alguns casais. Cada casal era composto de um morto e de um vivo, e aparentemente nada poderia distingui-los. Eu era convidada a entrar na dança, e foi então que compreendi que a multidão era composta também de vivos e mortos. Os mortos esperavam que os vivos os fizessem dançar, os fizessem viver. Por que, então, eu fugiria ou me subtrairia dessa obrigação de dar vida aos mortos? À medida que eu procurava um caminho para achar a saída, a multidão tornava-se cada vez mais densa, os mortos encostavam-se em mim, tocavam-me o rosto, como se fossem cegos. Eu me sentia cada vez mais angustiada para fugir, o que se tornava mais e mais difícil. No fundo do porão, vi uma abertura luminosa que me indicava a saída, segui os raios de luz para encontrar o caminho em direção à claridade, ao ar livre, deixando morrer os mortos. (Attias-Donfut, 1988, p. 244)

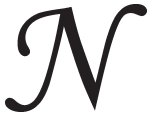

enhuma imagem dos estudos sobre gerações pôde deixar impressões tão fortes em mim quanto a descrição desse sonho que encerra o livro Sociologie des générations: l'empreinte du temps (1988), da pesquisadora das relações intergeracionais Claudine AttiasDonfut. É bem verdade que a relação entre diferentes gerações coloca em evidência um dos grandes problemas do homem: a finitude da vida. Nesse sentido, os processos de sucessão geracional, de maneira geral, tendem ao conflito, visto que podem determinar a morte de um dos grupos que se confrontam. Morte física ou simbólica, os processos de sucessão estão ligados à ideia do "fim de um tempo", bem como das práticas, valores e símbolos que o caracterizaram, e o início de "algo novo". Apesar desse entendimento, as imagens desse sonho permaneceram em mim como um incômodo, sobretudo a imagem dos mortos-vivos ainda desejosos de prolongarem sua atuação no mundo, necessitando, para isso, de serem animados pela "vida dos vivos", que ora aceitam entrar nesta mórbida dança, ora escapam dela, "deixando morrer os mortos".

Meu interesse pela relação entre diferentes gerações surgiu durante o doutorado, no qual desenvolvi uma pesquisa sobre duas gerações de metalúrgicos do ABC (Tomizaki, 2007). ${ }^{2}$ Confesso que, quando iniciei esse trabalho, a noção de geração não me parecia tão complexa 
como se revelou a posteriori. E, sobretudo, ainda não tinha ideia da intensidade das lutas silenciosas que se travavam entre as gerações, nem da importância que as alianças e atos de solidariedade entre elas podem ter nos processos de constituição de novas gerações. Enquanto a aproximação com as questôes teóricas dos estudos geracionais e os dados coletados no trabalho empírico me faziam mergulhar (de corpo, mente e alma) em uma realidade muito mais complexa e multifacetada do que a relação entre "mortos" e "vivos", as imagens do tal sonho continuavam a me incomodar, justamente porque pareciam indicar a quase impossibilidade da coexistência de diferentes gerações no mesmo espaço social. Como se os problemas de uma nova geração pudessem ser resolvidos, na medida em que esta conseguisse fugir do espaço que a obriga a conviver com a geração anterior, deixando lá trancafiados aqueles que, uma vez mortos, dependem dos vivos para continuarem a existir e agir no mundo. De fato, realizar um estudo geracional, sem dúvida alguma, significa estar preparado para analisar disputas, alianças, rupturas e continuidades de uma geração a outra. No entanto, talvez o fundamental não seja precisar os pontos de ruptura, superação ou morte de um grupo e ascensão de outro, mas, sobretudo, dimensionar de maneira cuidadosa e profunda as formas e intensidades assumidas pelas relações que unem e, ao mesmo tempo, distanciam as gerações.

Com base nos resultados da minha pesquisa de doutorado, neste artigo parto do princípio de que um dos processos que fortemente permeia as relações entre diferentes gerações é a socialização, que pode ser interpretada como um "ponto de encontro incontornável" entre elas (Tomizaki, 2006, 2007, 2008). ${ }^{3}$ Poderíamos dizer que processos socializadores incidem sobre um espaço fundamental de intersecção entre as gerações: a transmissão. Transmitir e herdar são duas facetas de um mesmo movimento que coloca as gerações diante do desafio de definir como devem se conduzir em relação à sua herança, que pode ir dos bens estritamente materiais aos totalmente simbólicos, bem como pode ser pensada tanto no plano das microrrelaçóes sociais (como as familiares), quanto em uma dimensão macrossocial (como os sistemas previdenciários, regulados pelo Estado). ${ }^{4}$

Assim, embora educação e gerações sejam realidades diversas, esses dois fenômenos sociais se encontram intrinsecamente ligados em função da necessidade de cada geração transmitir aos seus sucessores aquilo que considera fundamental para a preservação e continuidade 
Transmitir e herdar: o estudo dos fenômenos educativos...

da sua herança. Por outro lado, o próprio fenômeno geracional pode provocar mudanças tanto nos modos de se educar as novas gerações, quanto naquilo que deve ou não ser transmitido de uma geração a outra. Essa íntima relação entre educação e fenômeno geracional está na base do argumento defendido neste artigo de que os estudos da educação podem ser potencializados pelo uso da abordagem geracional. Entretanto, antes de entrarmos nesta discussão, é preciso passar por um exercício de definição do que pode ser considerado como uma geração.

\section{Gerações e relações intergeracionais: uma definição complexa}

Os estudos sobre gerações, em geral, são concordantes em um ponto fundamental: a noção de geração sofre um problema crônico de imprecisão conceitual, sendo utilizada, muitas vezes, de maneira excessivamente fluida e perigosamente influenciada pelo uso cotidiano (Brito da Motta, 2004; Mauger, 2009; Domingues, 2002).

De acordo com Attias-Donfut (1988), os primeiros estudos nas ciências humanas que tematizaram a relação entre diferentes gerações datam do século XIX e estão fortemente ligados à história, que, então, entendia a noção de geração como um instrumento metodológico para medir o tempo histórico e compreender seus movimentos. Entretanto, no início do século Xx, foram elaborados ensaios teóricos que, definitivamente, introduziram o conceito de geração nas ciências sociais. Dentre eles, se destacam os trabalhos de François Mentré (1920), José Ortega y Gasset (1926) e, sobretudo, Karl Mannheim (1928), cujo ensaio Das problem der generationen, de 1928, ainda é considerado o mais completo esforço de caráter sociológico na constituição de uma "teoria das geraçôes" e, portanto, constituirá o fio condutor deste artigo. ${ }^{5}$

Mannheim defendia que o fenômeno geracional deveria ser concebido como um tipo particular de situação social, e, portanto, somente a abordagem sociológica poderia dar conta de interpretá-lo em sua complexidade. Para delimitar quais são os fatores estruturais do fenômeno geracional, o autor propõe, em seu texto, uma "experiência mental", um exercício de imaginação que partiria da seguinte indagação: como seria a vida social se uma geração vivesse eternamente e jamais fosse substituida por outra? Para Mannheim, uma vez que as ciências sociais não podem lançar mão da "experimentação", "experiências mentais" como 
essa podem ser úteis para se isolar os fatores mais importantes dos fenômenos sociais. Podemos desdobrar essa questão em outras: uma sociedade, cujos membros nunca fossem substituídos, seria totalmente estática? Haveria espaço para novas aprendizagens? A mudança social seria possível? Para Mannheim,

(...) somente se esses homens utópicos dispusessem de uma consciência total utópica, se eles vivessem tudo que pode ser vivido, se eles pudessem saber tudo que pode ser conhecido e se eles dispusessem da flexibilidade necessária a um eterno recomeço, que a ausência da sucessão de gerações seria, em parte, compensada. ([1928] 1990, p. 48)

Logo, para o autor, as possibilidades de inovação dessa sociedade imaginária seriam muitíssimo reduzidas.

Ao contrário daquela sociedade imaginária, as sociedades humanas são perpassadas por desafios impostos pela sucessão geracional. E os fenômenos fundamentais que resultam da simples existência das gerações, sumariamente, são: (i) o surgimento permanente de novos agentes culturais; (ii) o desaparecimento de agentes culturais anteriores; (iii) o fato de os agentes de um conjunto geracional participarem somente de um período limitado de tempo no processo histórico; (iv) a necessidade de transmissão permanente de bens culturais acumulados; (v) a continuidade "eterna" da substituição das gerações. Cada um desses "dados elementares” carrega uma significação sociológica que deve ser considerada na análise da dinâmica geracional (Mannheim, [1928] 1990).

$\mathrm{O}$ estudo de Mannheim sobre as gerações se diferencia dos estudos anteriores a ele em dois aspectos fundamentais: primeiramente, ele procura dissociar os ritmos históricos da sucessão das gerações, criticando os autores que subordinaram a realidade das geraçôes à ideia da existência de um ritmo de geraçôes que poderia ser identificado em intervalos regulares (por exemplo, de 30 em 30 anos, como concebera Comte). Em segundo lugar, ele considera que a "pulsão" que conduz à formação e sucessão das gerações está fundamentalmente associada aos processos históricos de mudança social. De acordo com Mannheim, "a aceleração da dinâmica social é a causa da entrada em atividade da potencialidade de criação de novos impulsos de geração". Assim, a constituição de um novo "modo de geração", que possa ser identificado como tal pelas diferenças que demonstra em relação às gerações anteriores, é motivada pelas transformações na sociedade (Mannheim, [1928] 1990, p. 65). 
Transmitir e herdar: o estudo dos fenômenos educativos...

Vale esclarecer que a importância conferida por Mannheim aos processos sociais que estruturam e possibilitam a formação de novas gerações não deve ser interpretada como uma negação do autor ao fato de que

(...) a situação de geração se funda sobre a existência do ritmo biológico da vida humana: a vida, a morte, a duração limitada da vida e o envelhecimento (...). Mas, "estar fundado sobre" não significa o mesmo que "ser dedutível de" ou "estar incluso em". O fenômeno que é fundado sobre outro não poderia certamente existir sem o primeiro, mas ele oculta, em relação ao fenômeno fundador, algo mais que não pode ser deduzido do primeiro e é qualitativamente específico. (Idem, ibid., p. 44)

Nesse sentido, fica evidente que, para Mannheim, não podemos conceber o surgimento de novas geraçôes somente em função do nascimento de novos membros nas sociedades. O fato de determinados indivíduos terem nascido em um mesmo período histórico - o que, naturalmente, os fará avançar "juntos" nos ciclos da vida - não é suficiente para concluir que estes constituirão uma geração. Assim, o critério etário constitui elemento importante na definição do fenômeno geracional; entretanto, a contemporaneidade cronológica constitui apenas uma situação de pertencimento potencial a uma geração. As gerações possuem, na sucessão biológica, sua condição de existência concreta. No entanto, elas não se efetivam como tal sem a constituição de uma situação material e simbólica capaz de criar o pertencimento a uma coletividade.

A situação de classe $^{6}$ e a situação de geração (pertencimento a classes de idade vizinhas) têm em comum o fato de circunscreverem, em função de sua situação específica no espaço sócio-histórico, os indivíduos em um campo determinado de possíveis e favorecerem, assim, um modo específico de experiência e de pensamento, bem como um modo específico de intervenção no processo histórico. Cada situação afasta diretamente um grande número de modos de experiência, de pensamento, de maneiras de sentir e agir possíveis e restringe a margem do jogo dos efeitos da individualidade a possibilidades precisas e limitadas (...). É inerente a cada situação a tendência a um modo de comportamento, uma maneira de sentir e de pensar determinados. (Idem, ibid., p. 45; grifos do autor)

A partir dessas consideraçóes, Mannheim defende o argumento de que existe uma analogia entre a situação de classe e a situação de geração, dado que "estar" em uma ou em outra dessas "situaçôes" sempre 
significaria estar ligado a determinaçôes sócio-históricas muito específicas, capazes de constituir modos de pensar e agir bastante diversos. Assim, como "o proletário não se apropria de certos bens culturais senão sobre um modo próprio à sua camada social”, também indivíduos de gerações diferentes vão conceber e se apropriar do mundo e seus acontecimentos de maneira peculiar, desenvolvendo um modo próprio de atuação na sociedade (Mannheim, [1928] 1990). ${ }^{7}$

Importante destacar aqui duas dimensões da relação entre "situação de classe" e "situação de geração": de um lado, como já foi dito, essas duas "situaçóes" são análogas (embora Mannheim destaque que são realidades diferentes), sobretudo na sua capacidade de afetar as experiências e a formação daqueles que se encontram ligados a elas. Por outro lado, a vivência da condição de classe é capaz de influir fortemente na experiência propriamente geracional. Isso porque os indivíduos que partilham uma mesma posição social têm, evidentemente, chances bem maiores de experimentar situaçōes comuns do que os indivíduos de diferentes classes sociais. De acordo com Mannheim, é preciso ter nascido na mesma comunidade de vida social e histórica, que aponte para uma mesma comunidade de destino, para que seja possível a criação de um modo de comportamento, de uma maneira de sentir e de pensar próprios a um grupo. Assim,

(...) só se pode falar de uma situação de geração (...) na medida em que os indivíduos que entram simultaneamente na vida participem potencialmente em acontecimentos e experiências capazes de criar laços entre eles. Somente um mesmo quadro de vida histórico-social permite que a situação definida pelos nascimentos no tempo cronológico torne-se uma situação sociologicamente pertinente. (Mannheim, [1928] 1990, p. 52; grifos meus)

Assim, os indivíduos, para pertencerem a uma geração, devem ter em comum uma mesma situação sócio-histórica ou uma mesma condição de existência que norteie e delimite (evidentemente, de forma desigual) suas possibilidades de acesso aos bens materiais e simbólicos disponíveis nas sociedades. A transmissão dos "conteúdos sociais", nas palavras de Mannheim, é sempre orientada de acordo com os grupos sociais aos quais os indivíduos estão ligados, mesmo nos casos em que os mesmos conteúdos são oferecidos ou estão acessíveis a todos os membros da sociedade. Assim, o pertencimento a uma geração passa, 
Transmitir e herdar: o estudo dos fenômenos educativos...

necessariamente, pelo pertencimento a um grupo específico, e pertencer a um grupo não significa apenas aderir aos valores que lhes são próprios, mas, sobretudo, ser capaz de perceber o mundo e de se entender no mundo com os instrumentos e as nuances próprias a esse grupo (Mannheim, op. cit.).

Entretanto, não se pode desconsiderar o peso das idades sobre as experiências dos individuos, mesmo entre aqueles ligados por uma situação de classe comum. Para realizar essa discussão, Mannheim se apoia na ideia desenvolvida por Wilhelm Pinder (1926) da "não-contemporaneidade dos contemporâneos":

No mesmo tempo cronológico, vivem gerações diferentes, mas, apesar do tempo vivido ser o mesmo tempo real, de fato, elas vivem todas em um tempo interior completamente diferente do ponto de vista qualitativo. (Mannheim, [1928] 1990, p. 34)

Cada um vive com homens da mesma idade e de idades diferentes confrontados com uma multidão de possibilidades simultâneas. Para cada um o mesmo tempo é um outro tempo, quer dizer, uma outra idade de si mesmo, que ele só partilha com aqueles da sua idade. (Pinder, 1926, p. 21, citado por Mannheim, op. cit., p. 35)

Exemplo disso seria a separação que Mannheim realiza entre a "memória apropriada" pela convivência com outras gerações e a "memória adquirida" pelos próprios indivíduos, por meio de experiências vivenciadas "em primeira pessoa", e que, portanto, seria muito mais carregada de sentidos do que aquelas que são transmitidas por membros de gerações antecessoras. ${ }^{8}$

Creio que, neste momento, já temos condições de circunscrever duas primeiras dimensões fundamentais do fenômeno geracional: idade e situação de classe. Todo e qualquer estudo que se proponha a analisar as práticas, percepçóes e discursos de um dado grupo social em uma perspectiva geracional precisa, necessariamente, partir da composição dessas duas primeiras variáveis. Além disso, é preciso ressaltar que idade e situação de classe só farão sentido na compreensão de uma geração na medida em que puderem ser relacionadas a um conjunto significativo de experiências compartilhadas pelos membros do grupo estudado. Assim, somente a conjugação desses três elementos (idade, situação de classe e experiências comuns) pode revelar, de modo preciso e refinado, os contornos de uma geração.? 
Embora a análise das experiências comuns seja fundamental na definição de uma geração, é preciso problematizar o lugar atribuído a esta variável. De acordo com Domingues (2002), o acento sobre a importância das experiências comuns na constituição das gerações pode pressupor que estas configurem, de algum modo, coletividades homogêneas, com certo grau de centramento. Tais grupos se definiriam, então, somente pelas suas próprias experiências como coletividade e, portanto, em independência ou autonomia em relação ao que se passa com outras gerações. Nesse sentido, para o autor, a concepção de Mannheim perderia de vista, assim, a relação entre as gerações como elemento fundamental na constituição destas. Embora Mannheim afirme a importância da influência mútua entre as gerações, com destaque para os processos de transmissão e socialização, como será discutido mais adiante, tendo a concordar, de fato, que seu texto enfatiza mais a questão da delimitação do que pode ou não ser definido com um conjunto geracional, do que a importância que as relações intergeracionais exercem na constituição das gerações. Ainda no âmbito dessa crítica, AttiasDonfut reivindica que as experiências que unem as gerações não podem ser pensadas somente como "experiências concretas", mas como experiências também de ordem simbólica. Isso parece ser bastante razoável e não necessariamente discordante do pensamento de Mannheim, visto que este considerava a existência de diferentes níveis de participação no fenômeno geracional.

Mannheim desenvolveu um quadro conceitual bastante preciso no que tange aos critérios de pertencimento a uma geração. De acordo como o autor, a situação de geração não pode ser considerada como um conjunto geracional; este último é mais que uma simples situação de geração, que apenas guarda possibilidades potenciais. O conjunto geracional não se limita à presença de um indivíduo em uma unidade histórico-social determinada, sendo necessário que este possua uma ligação com o destino comum daquele grupo. A unidade de geração, por sua vez, é um laço bem mais concreto que aquele que funda o conjunto geracional. Poderíamos dizer que as unidades de geração surgem no interior das chamadas "comunidades de destino". Elas não se caracterizam somente pela participação fluida de indivíduos diferentes em um conjunto de acontecimentos vividos em comum. Um grupo se constitui como uma unidade de geração quando é capaz de construir uma reação unitária, uma ressonância comum, organizada de maneira 
Transmitir e herdar: o estudo dos fenômenos educativos...

análoga por indivíduos que estão precisamente ligados entre si. Isso não quer dizer que se trate de um grupo homogêneo ou sempre concordante em suas ações ou ideias. No interior das unidades de geração desenvolvem-se os grupos concretos que podem, inclusive, ser adversários entre si, importando apenas que estejam ligados aos mesmos problemas, se remetam e problematizem as mesmas questôes (Mannheim, [1928] 1990). Seguindo essa mesma lógica, poderíamos concluir que, assim como existem diferentes níveis de implicação dos indivíduos no fenômeno geracional, também as experiências capazes de criar laços entre os indivíduos podem atingir os membros de uma geração com diferentes intensidades, portanto, sendo algumas experiências concretas e outras simbólicas ou subjetivamente vivenciadas. ${ }^{10}$

Além disso, é preciso ressaltar que a perspectiva relacional é fundamental para a compreensão da formação de diferentes gerações: ninguém é jovem senão em relação àqueles que são reconhecidos como velhos e vice-versa (Bourdieu, 1984). Da mesma forma, nenhum grupo pode ser reconhecido como portador de uma "inovação" se não há clareza do que exatamente seria o "ultrapassado". Nesse sentido, concordo com a proposta teórico-metodológica de Attias-Donfut de que os estudos geracionais, na verdade, devem ser estudos sobre a "dinâmica das geraçôes", entendida como o processo de ação de umas geraçôes sobre as outras, que se desenrola no curso de um período dado (Attias-Donfut \& Lapierre, 1994).

Attias-Donfut $(1988,2000)$ critica ainda a ideia, atribuída a Mannheim, segundo a qual "eventos fundadores" confeririam singularidade às gerações. De acordo com a autora, relacionar uma geração a um evento ou a um momento histórico específico pode fixá-la a um só período de sua formação (que coincidiria com sua "fase histórica fundadora") e tal cristalização levaria, por consequência, ao ocultamento das influências históricas ulteriores e das marcas impressas sobre esta geração ao longo da totalidade do seu percurso. Além disso, a autora considera que, mesmo em períodos não caracterizados por transformações sociais, econômicas ou políticas de grande vulto, assistimos constantemente à formação de novas gerações: "Cada indivíduo se situa, dentre seus pares e com eles, no período da história social a qual ele pertence, sendo este período ordinário ou extraordinário, ele se identifica com sua 'geração histórica' e se diferencia das outras em um processo fundamental de apropriação do tempo social e histórico" (Attias-Donfut, 2000, 
p. 645). Os acontecimentos, nesta perspectiva, sobretudo aqueles que têm "importância maior", afetariam todos os membros de uma sociedade: eles seriam, por definição, multigeracionais e a profundidade da marca que eles poderiam deixar tem relação com o nível de exposição de uns e de outros, segundo sua idade e situação de classe, mas também segundo sua situação de ator, testemunha ou vítima.

Consideradas essas críticas, creio que seja fundamental avançarmos um pouco mais na delimitação dos aspectos que podem ser considerados imprescindíveis na constituição de um conjunto geracional. Em primeiro lugar, acredito que seja pertinente a crítica de AttiasDonfut no que diz respeito à associação entre as condições de possibilidade de formação de novas geraçốes e os chamados "eventos fundadores". Embora estes possam constituir marcos importantes na formação de algumas gerações, não necessariamente todas as gerações precisam ser impactadas por eles para existirem. Por outro lado, no que tange às mudanças sociais como determinantes da formação de conjuntos geracionais que, de fato, podem ser tomados como tal pela "novidade" que apresentam em relação às gerações anteriores, tendo a concordar com a interpretação de Mannheim: somente transformações sociais são capazes de apresentar desafios suficientemente significativos, a ponto de provocarem o surgimento de novos comportamentos e atitudes nos grupos sociais. Para este autor, novas geraçóes trariam uma "nova abordagem" sobre o mundo, o que significaria "novas atitudes na apropriação, transformação e desenvolvimento do que existe” (Mannheim, [1928] 1990, p. 58). No mínimo, poderíamos afirmar que as pesquisas que se debruçam sobre períodos de transformação social poderão ser muito mais frutíferas no que tange à possibilidade de delinear, com clareza, as diferenças (e semelhanças) entre conjuntos geracionais distintos.

Assim, há que se considerar também, nos estudos geracionais, a conjuntura histórica do periodo no qual se inscrevem as geraçóes assumidas como objeto de estudo. Se o pesquisador não tiver clareza das possibilidades e coerçóes (objetivas e simbólicas) impostas ao grupo estudado, em função do período histórico no qual ele se formou e se desenvolveu como conjunto geracional, tampouco lhe será possível compreender adequadamente os outros condicionantes da situação de geração anteriormente explicitados (idade, situação de classe, experiências comuns e as relações intergeracionais). 
Transmitir e herdar: o estudo dos fenômenos educativos...

Finalmente, chegamos ao último aspecto que consideramos imprescindível para se pensar o estudo das gerações, sobretudo no interior das pesquisas sobre educação, e que, praticamente, não é considerado por Mannheim: a dimensão familiar ou das relações de parentesco. Para Mauger (2009, p. 112), "uma geração familiar é filha de seus pais, uma geração social é, por sua vez, filha dos seus anos de formação, filha do seu tempo e de sua idade". Gerações familiares e gerações sociais, de acordo com o autor, estão diretamente relacionadas: se os membros de uma geração familiar são ligados pelos laços de parentesco, eles também estão ligados a um sistema escolar ou a uma configuração específica de mercado de trabalho. Logo, as gerações familiares nunca se encontram descoladas da realidade das geraçôes sociais ou históricas. Mais do que isso, diferentes gerações familiares podem coincidir com gerações sociais também diversas, redundando em conflitos que perpassam desde o âmbito familiar até os espaços públicos, como o sistema de ensino ou determinados campos de atuação profissional. ${ }^{11}$ Por outro lado, na medida em que uma geração social ou histórica pode ser reconhecida como tal, por possuir um "modo de geração" específico, não se pode ignorar que este foi produzido também no âmbito familiar, por meio dos processos de socialização específicos dessa instância socializadora, que são continuamente influenciados pela ordem social, política e econômica vigente. Assim, é possível dizer que o pertencimento a uma geração social ou histórica pode ser tributário das relações entre gerações familiares. ${ }^{12}$

Poderíamos dizer que chegamos, assim, aos aspectos fundamentais que devem compor o quadro de análise dos conjuntos geracionais: (i) idade; (ii) situação de classe; (iii) experiências comuns (concretas ou simbólicas); (iv) relação com outras gerações (sucessoras ou antecessoras); (v) conjuntura histórica (social, econômica e politica) na qual se inscrevem as geraçôes; (vi) famílialrelaçôes de parentesco.

A tarefa de lidar com essas diferentes e fundamentais dimensōes do fenômeno geracional aponta para uma exigência teórico-metodológica: a delimitação de diferentes gerações é necessariamente construída pelo trabalho empírico realizado sobre "gerações concretas". Dito de outra forma, os estudos geracionais não podem ser concebidos "no vácuo": as gerações são formadas e existem em sua concretude histórica e social. Portanto, uma vez consideradas essas dimensões fundamentais ora citadas, cabe ao pesquisador que assume tal abordagem precisar empiricamente 
quais são os contornos que possibilitam que o grupo social estudado possa ser concebido como uma geração (Attias-Donfut, 2000).

Nesse sentido, atualmente, parece possível e desejável que os estudos de caráter geracional possam conceber diferentes nuances na definição dos conjuntos geracionais, considerando, para isso, a necessidade de ajustar esta noção às características tanto do grupo estudado, quanto do problema de pesquisa que orienta a investigação, sem que isso se torne mais um estímulo à imprecisão do conceito de geração. Exemplo desse movimento poderia ser uma pesquisa realizada por Attias-Donfut (2000), cuja definição de geração envolveu três dimensões diferentes dessa mesma realidade: (i) gerações familiares: ligadas estritamente por laços de parentesco; (ii) geraçôes históricas: definidas como o conjunto de pessoas nascidas em um mesmo período, partilhando experiências, referências e influências sociais extraídas do seu tempo comum; (iii) geraçôes do "welfare": grupos sociais resultantes do processo de institucionalização do curso da vida pela ação do Estado, divididos nos seguintes "períodos": educação, trabalho e aposentadoria. Trata-se de uma pesquisa sobre três gerações, que abarcou 4.668 pessoas, pertencentes a 1.958 famílias diferentes, cujos resultados são muito interessantes. Entretanto, um exame rápido já poderia indicar que, no mínimo, a ideia de "gerações do welfare" dificilmente seria operativa em pesquisas de caráter geracional que assumam como sujeitos determinados grupos sócio-profissionais no Brasil, cuja condição de (sub)existência ainda guarda pouca semelhança com os ciclos de vida institucionalizados pelo Estado em países como a França (pelo menos para parte significativa de sua população). Assim, os pesquisadores que laçarem mão da abordagem geracional, necessariamente, além de dominarem a discussão teórico-metodológica que permeia essa área de estudos, também precisarão ser sensíveis na opção dos elementos do fenômeno geracional que deverão ser privilegiados em suas análises, eventualmente trazendo à tona outras dimensões deste fenômeno, ainda pouco exploradas.

Por uma abordagem geracional dos fenômenos educativos

Uma vez que este artigo pretende discutir as contribuições que a abordagem geracional pode trazer para a análise sociológica do fenômeno da educação, seria incontornável tocar na questão da especificidade 
Transmitir e herdar: o estudo dos fenômenos educativos...

dos estudos da área de sociologia da educação. Nesse sentido, dois aspectos fundamentais da sociologia da educação discutidos por Spósito (2007), no texto "Uma perspectiva não escolar no estudo sociológico da escola", parecem-nos fundamentais para este debate: primeiramente, o fato de que, embora a expressão "sociologia da educação" possa ser considerada legítima como área de pesquisa já consolidada, a rigor, ela pode também ser "imprópria", nas palavras de Florestan Fernandes; não somente ela, mas todas as "sub-áreas" que surgem de um movimento de divisão "indefinida" dos campos da sociologia: sociologia da cultura, do conhecimento, do trabalho, do lazer etc., que podem redundar no empobrecimento das análises dos fenômenos sociais. Segundo a autora, a área de sociologia da educação deveria, portanto, estar atenta para não ser confundida com uma arbitrária divisão disciplinar "que não encontra eco nos processos sociais reais", o que passa pela simples reafirmação da sua tarefa primordial: "examinar, sob o ponto de vista sociológico, os fenômenos educativos”. Por outro lado, Spósito aponta ainda que, no Brasil e em outros países, é inegável que a instituição escolar e o sistema de ensino têm sido priorizados como objetos nos estudos da sociologia da educação. Entretanto, é preciso lembrar que a análise sociológica da educação recobre um campo infinitamente mais amplo, visto que os mecanismos por meio dos quais os membros das sociedades transmitem seus saberes, comportamentos, condutas e valores são largamente variados. De acordo com a autora, no Brasil existem esforços promissores - embora ainda incipientes - na expansão do escopo dos objetos e problemas relacionados ao estudo sociológico da educação (Spósito, 2007, p. 19 e 20).

Feitas essas duas importantes considerações sobre a sociologia da educação, e considerando o que foi apresentado neste artigo até este ponto, podemos caminhar rumo a algumas conclusões, de caráter provisório, a respeito das contribuições da abordagem geracional para essa área de pesquisa. $\mathrm{O}$ argumento aqui defendido é que o uso da abordagem geracional pode significar a radicalização da análise sociológica dos fenômenos educativos, não sendo, evidentemente, a única forma de realizar tal tarefa.

De acordo com Attias-Donfut, Jano (ou Janus, em latim) poderia simbolizar bem a dinâmica das gerações em nossa sociedade: a divindade romana, representada com uma cabeça e duas faces, sempre voltadas para lados opostos, era capaz de olhar o passado e o futuro ao 
mesmo tempo, simbolizando tanto o "início" quanto o "fim”. O movimento de sucessão das gerações faz com que sempre haja um grupo que olha para frente e outro que se volta para o que já passou; ou melhor, concomitantemente, existem vários grupos que representam o futuro e outros tantos que podem ser identificados com o passado. Penso que a dinâmica intergeracional, que possibilita que "as faces" das gerações sejam viradas em direção ao passado, encontra apoio nos processos de socialização mediados por diferentes instâncias socializadoras (família, escola, trabalho, igreja etc.), que balizam todo e qualquer encontro entre gerações

Para Mannheim, “o essencial em todo processo de transmissão é que a nova geração cresce imersa em comportamentos, sentimentos e atitudes herdadas". E essa herança será transmitida para a nova geração em um processo de "mão dupla": "não é somente o professor que educa o aluno, mas também o aluno educa o professor. As gerações se influenciam mutuamente". Vale destacar ainda que o autor estabelece uma nítida diferença entre o que é aprendido por meio da "instrução" ou ensino e toda uma gama de "conteúdos e atitudes" transmitidos e herdados de modo inconsciente, que seriam os mais importantes para o fenômeno geracional. Assim, a coesão das unidades geracionais pode ser entendida como o resultado da socialização (Mannheim, [1928] 1990, p. 54 e 56).

Entendemos que as experiências socializadoras (primárias e secundárias) são práticas sociais definidoras das possibilidades e limites objetivos e subjetivos - das trajetórias dos indivíduos no espaço social. E não se trata, evidentemente, de um processo de transmissão "automática" de conteúdos, valores, normas e regras de uma geração a outra. Tendo em vista superar as críticas ao tratamento determinista que, a partir da obra de Emile Durkheim, este termo recebeu no interior da sociologia, os processos de socialização serão aqui definidos como o desenvolvimento de uma dada representação do mundo, mediada pelas experiências "oferecidas" pelo espaço social ao qual os individuos têm acesso. Assim, a representação que as pessoas desenvolvem a respeito de si mesmas, do mundo social e do lugar ocupado por elas neste mundo é o "resultado" (nunca finalizado e, portanto, em contínua transformação) de um processo lento, gradual e constante, que resulta em um "código simbólico". Este código não pode ser comparável a um "pacote" de crenças e de valores idênticos aos da geração precedente, mas a um sistema 
Transmitir e herdar: o estudo dos fenômenos educativos...

complexo de referência e de avaliação do real que permite aos indivíduos assumirem um padrão de comportamento identificável com um determinado coletivo (Bourdieu, 1993, 1998; Durkheim, [1922] 1975; Percheron, 1993; Tomizaki, 2008).

A socialização, nessa perspectiva, como dito anteriormente, torna-se fatalmente um encontro de gerações, um encontro necessário e incontornável, no qual, entre disputas e alianças, diferentes gerações definirão, umas em relação às outras, as continuidades e rupturas de determinados "modos de geração". Sendo assim, os processos socializadores são parte constitutiva da "dinâmica das gerações", no sentido dado por Attias-Donfut a este termo.

A educação, entendida como prática social, é permeada por uma série de condicionantes sociais, econômicos e políticos, o que parece ser uma afirmação bastante óbvia. Entretanto, desenvolver estudos que, de fato, sejam capazes de compreender as práticas educativas - intencionais ou não - como parte de uma configuração social e histórica específica, relacionando os fios que ligam tais práticas à organização econômica e do poder em uma sociedade, nem sempre é uma tarefa simples e, muito menos, óbvia. É justamente nesse sentido que acredito que o uso da abordagem geracional na compreensão dos fenômenos educativos pode significar a radicalização da análise sociológica das práticas educativas, visto que, como foi discutido ao longo de todo texto, a análise da dinâmica das gerações exige um esforço teórico e metodológico de constituição de um quadro analítico preciso sobre os determinantes sociais do fenômeno geracional. Sendo assim, tomando como ponto de partida a compreensão minuciosa dos elementos que estruturam a situação de geração como uma situação social específica, torna-se possível relacionar as mais diversas práticas educativas a determinadas dinâmicas intergeracionais, ou seja, relacioná-las às exigências (limites e possibilidades) que delineiam "como" e "o que" deve ser transmitido de uma geração a outra. Sendo assim, pensar a educação em uma perspectiva geracional significa enraizá-la em seu pertencimento social, atribuindo-lhe sentidos mais amplos, fortemente pautados no movimento das interações sociais.

Recebido em maio de 2010 e aprovado em junho de 2010. 


\section{Notas}

1. Gostaria de destacar que todas as interpretações e sentidos atribuídos neste texto ao sonho descrito por Attias-Donfut são de minha inteira responsabilidade (e risco), ou seja, nenhuma dessas interpretações foi indicada por ela própria, nem possui qualquer relação com a leitura que faço de suas concepções sobre as relações intergeracionais.

2. Trata-se de uma pesquisa sobre os processos de transmissão de comportamentos em relação ao trabalho e à política entre duas gerações de metalúrgicos: aqueles que foram jovens no final da década de 1970 e os jovens do final de 1990. O locus da pesquisa foi a fábrica da antiga Mercedes Benz do Brasil, atualmente Daimler do Brasil, na qual realizei 52 entrevistas de caráter biográfico, observaçôes e pesquisa em arquivos do sindicato e da empresa ao longo de aproximadamente um ano, entre 2002 e 2003.

3. Sem dúvida alguma, foi a experiência empírica do doutorado, bem como os desafios teóricos e metodológicos impostos por ela que pautaram as reflexôes apresentadas neste artigo. Assim, mobilizarei, ao longo do texto - em notas de rodapé -, alguns dados da pesquisa, tendo em vista "materializar" a discussão teórica aqui apresentada.

4. Para uma discussão sobre a diferença entre transmissão de bens materiais e bens simbólicos, ver Mauger (2009).

5. Infelizmente, como não domino o idioma alemão, trabalhei com uma tradução do célebre texto de Karl Mannheim. Optei pelo uso da tradução feita por Gérard Mauger e Nia Perivolaropoulou do alemão para o francês, publicada em 1990, pela Éditions Nathan. Assim, os trechos do texto de Mannheim que serão citados ao longo do artigo foram traduzidos por mim diretamente do francês (Mannheim, [1928] 1990).

6. Para Mannheim, "Por situação de classe pode-se entender, em um sentido mais amplo do termo, uma situação análoga de determinados indivíduos no interior da estrutura econômica e de poder de uma dada sociedade, situação esta que contém o germe dos seus destinos" (Mannheim, [1928], 1990, p. 42). As expressões "situação de classe" ou "condição de classe" serão utilizadas aqui neste sentido.

7. Provavelmente, este trecho seja suficiente para chamar a atenção dos leitores de Pierre Bourdieu sobre as similaridades entre sua teoria do habitus e a teoria das geraçóes de Mannheim. Gérard Mauger, cuja tradução do ensaio de Mannheim foi utilizada neste artigo, discute, de forma bastante pertinente, no "Postface" dessa edição, as possíveis mediaçôes entre essas duas teorias.

8. A esse respeito, gostaria de citar um exemplo da minha pesquisa: trata-se das diferenças de significados atribuídos à Tribuna Metalúrgica, informativo diário do Sindicato dos Metalúrgicos do $\mathrm{ABC}$, pelas duas gerações analisadas em minha tese. A leitura da Tribuna é um "hábito" dos trabalhadores mais velhos, carregado de um forte significado político que remete ao período em que a imprensa sindical não ultrapassava os "portôes" das fábricas, a não ser clandestinamente, dentro dos macacôes dos operários. Os mais jovens conhecem as histórias contadas pelos mais velhos: os "jornaizinhos do sindicato" tinham que ser lidos nos banheiros, cada um lia e deixava para o próximo; apesar disso não conseguem atribuir o mesmo sentido à leitura da Tribuna, que hoje pode ser encontrada toda manhã nas portas das fábricas do ABC Paulista. Grosso modo, para os mais velhos, entrar na fábrica lendo a Tribuna é ato político; para os mais jovens, não passa de um meio de se informar e que, portanto, é mais valorizado em determinados períodos, como de campanha salarial.

9. Em minha pesquisa de doutorado, trabalhei inicialmente com um recorte artificial para definir as duas geraçôes: a primeira seria composta pelos trabalhadores que eram jovens

Educ. Soc., Campinas, v. 31, n. 111, p. 327-346, abr.-jun. 2010

Disponível em <http://www.cedes.unicamp.br> 
Transmitir e herdar: o estudo dos fenômenos educativos...

(entre 18 e 25 anos) entre os anos de 1978 e 1982; a segunda geração, por sua vez, também seria constituída por aqueles que eram jovens entre 1998 e 2002. Ao longo do processo de análise das experiências constitutivas das duas gerações, esse primeiro recorte, pautado exclusivamente na idade e na participação em períodos históricos diferentes, pôde ser substituído por uma classificação muito mais precisa e refinada. Exemplo disso é o fato de que somente três anos de idade separavam o mais novo membro da primeira geração e o mais velho da segunda. Essa aproximação etária entre os dois conjuntos geracionais foi resultado da constituição de um quadro analítico fundamentalmente constituído pelas experiências vivenciadas pelos membros das gerações estudadas (bem como pela maneira como estas foram percebidas por eles), combinada com seus efeitos sobre os modos desses indivíduos perceberem o mundo e seu lugar nele. Logo, o problema da "classificação" dos depoentes que ficavam no limite entre as duas geraçōes, do ponto de vista etário, ou mesmo em relação à vivência de determinadas experiências, só pôde ser resolvido na medida em que pude identificar a existência de um habitus de geração e pude defini-lo em seus três componentes: cognitivo (eidos), normativo (ethos) e corpóreo-afetivo (bexis).

10. Retomando mais uma vez minha pesquisa de doutorado, fiz a opção teórico-metodológica de entrevistar trabalhadores cujos níveis de envolvimento político eram muito diversos, especialmente em relação a uma "realização específica" que é atribuída aos "metalúrgicos do ABC": a formação do Partido dos Trabalhadores (PT). Evidentemente, é sabido que a formação do PT é tributária de um processo histórico muito mais complexo, mas não é o caso aqui discutir tal ponto. O que nos interessa, para os fins deste artigo, é a constatação de que mesmo os trabalhadores que não se envolveram diretamente na formação do partido concebem que o PT, de fato, foi criado pela categoria metalúrgica como um todo, e sentemse ligados a essa memória. Assim, mesmo não vivenciando "experiências concretas" na formação do partido, subjetivamente percebem-se como atores do movimento que tornou possível sua criação. $\mathrm{O}$ mesmo sentimento se repete em relação à participaçãa no movimento grevista iniciado em 1978.

11. Um exemplo importante seria a questão específica dos efeitos do alongamento da escolarização de uma geração a outra, tanto no âmbito das relações familiares quanto no conjunto da sociedade, tema que foi brilhantemente discutido por Sthéphane Beaud \& Michel Pialoux $(1999,2003)$ a propósito de duas gerações de operários franceses.

12. Outro rico exemplo de pesquisa que aborda a estreita relação entre as dimensões familiares e socioeconômicas na constituição das relações intergeracionais é o livro L'héritage refusé, de Patrick Champagne (2002).

\title{
Referências
}

\section{ATTIAS-DONFUT, C. Sociologie des générations: l'empreinte du temps. Paris: Universitaire de France, 1988.}

\author{
ATTIAS-DONFUT, C. (Org.). Les solidarités entre générations: \\ vieillesse, famille, État. Paris: Nathan, 1995.
}

\begin{abstract}
ATTIAS-DONFUT, C. Rapports de générations: transfert intrafamiliaux et dynamique macrosociale. Revue Française de Sociologie, Paris, v. 41, n. 4, p. 643-684, 2000.
\end{abstract}


ATTIAS-DONFUT, C.; LAPIERRE, N. La dynamique des générations. Communications, Paris, v. 59, n. 59, p. 5-13, 1994.

BEAUD, S.; PIALOUX, M. Retour sur la condition ouvrière: enquête aux usines Peugeot de Sochaux-Montbéliard. Paris: Fayard, 1999.

BEAUD, S.; PIALOUX, M. Violences urbaines, violence sociale: genèse des nouvelles classes dangereuses. Paris: Fayard, 2003.

BOURDIEU, P. La “jeunesse” n'est qu'um mot. In: Bourdieu, P. Questions de sociologie. Paris: Minuit, 1984. p. 143-154.

BOURDIEU, P. Les contradictions de l'héritage. In: Bourdieu, P. La misère du monde. Paris: Seuil, 1993. p. 1091-1103.

BOURDIEU, P. Futuro de classe e causalidade do provável. In: Nogueira, M.A.; Catani, A. (Org.). Escritos de educação. São Paulo: Vozes, 1998. p. 54-69.

BRITO DA MOTTA, A. Gênero, idades e geraçôes (Introdução). Caderno CRH, Salvador, v. 17, n. 42, p. 349-355, 2004.

CHAMPAGNE, P. L'héritage refusé: la crise de la reproduction sociale de la paysannerie française (1950-2000). Paris: Seuil, 2002.

DOMINGUES, J.M. Geraçôes, modernidade e subjetividade. Tempo Social, São Paulo, v. 14, n. 1, p. 67-89, 2002.

DURKHEIM, E. Educação e sociologia. Trad. de Lourenço Filho. 10. ed. São Paulo: Melhoramentos, [1922] 1975.

MANNHEIM, K. Le problème des générations. Paris: Nathan, [1928] 1990.

MANNHEIM, K. Das problem der generationen. In: Wissenssoziologie. Berlin: Herman Luchtearhand, 1928.

MAUGER, G. Générations et rapport de générations. Daimons: Revista Internacional de Filosofia, Espanha, n. 46, p. 109-126, 2009.

MENTRÉ, F. Les générations sociales. Paris: Bossard, 1920.

ORTEGA Y GASSET, J. El tema de nuestro tiempo. Madrid: Revista do Occidente, 1923. 
PERCHERON, A. La socialisation politique. Paris: A. Colin, 1993.

PINDER, W. Das problem der generation in der Kunstgeschichte Europas. Berlin: Frankfurter Verlaganstalt, 1926.

SPÓSITO, M.P. Uma perspectiva não escolar no estudo sociológico da escola. In: PAIXÃO, L.; ZAGO, N. (Org.). Sociologia da Educação: pesquisa e realidade brasileira. Petrópolis: Vozes, 2007. p. 19-43.

TOMIZAKI, K. A herança operária entre a fábrica e a escola. Tempo Social, São Paulo, v. 18, n. 01, p. 153-171, 2006.

TOMIZAKI, K. Ser metalúrgico no $A B C$ : transmissão e herança da cultura operária entre duas gerações de trabalhadores. Campinas: Centro de Memória da UNICAMP; Arte Escrita; FAPESP, 2007.

TOMIZAKI, K. Socializar para o trabalho operário: o SENAI-MercedesBenz. Tempo Social, São Paulo, v. 20, n. 1, p. 69-94, 2008. 